INTRODUCCIÓN

\title{
De los trasplantes a las traducciones legales: Introducción a la tesis de la no-Americanización en Langer
}

\author{
From Transplants to Legal Translations: \\ An Introduction to Langer's Non-Americanization Thesis
}

Antonella Donnes*

Recepción y evaluación de propuesta: $2 / 5 / 18$

Aceptación: 2/6/18

Recepción y aceptación final: 9/4/2019

Resumen: En lo que constituye el núcleo central de esta Discusión, Máximo Langer nos sumerge en el mundo del derecho comparado y nos invita a reflexionar sobre las influencias y relaciones entre distintos sistemas en el ámbito del derecho procesal penal. Las recientes reformas de corte acusatorio implementadas en los sistemas procesales continentales europeos y latinoamericanos sugieren una "americanización” del proceso penal en tales países. No obstante, Langer se propone ir más allá de las apariencias y refutar esta idea mediante un análisis del modo en que ha sido introducido el instituto estadounidense del plea bargaining en cuatro jurisdicciones representativas de la tradición continental europea y latinoamericana. Bachmaier, Correa Robles y Engländer evalúan la posición presentada y enriquecen el debate desde las perspectivas de sus países de origen.

Palabras clave: Plea bargaining, justicia negociada, proceso penal, sistema inquisitivo, sistema acusatorio, trasplante legal, traducción legal.

* Abogada, Profesora de la Universidad de Buenos Aires (UBA), Buenos Aires, Argentina. Correo electrónico: donnes@estudio.name 


\begin{abstract}
Regarding the core of this discussion, Máximo Langer immerses us into the world of comparative law and invites us to reflect on the influences and relationships between the different systems in the field of criminal procedure. The new accusatory reforms implemented in the European and Latin American continental procedural systems may imply an Americanization of the criminal process in such countries. However, Langer intends to go beyond appearances and refute this thesis through an analysis of how the U.S.'s institute of plea bargaining has been introduced in four jurisdictions representative of the continental European and Latin American tradition. Bachmaier, Correa Robles and Engländer critically evaluate the position and enrich the debate from the perspectives of their countries of origin.
\end{abstract}

Keywords: Plea bargaining, negotiated justice, criminal process, inquisitorial system, adversarial system, legal transplant, legal translation.

\title{
1. Introducción
}

En lo que constituye el núcleo central de esta Discusión, Máximo Langer nos sumerge en el mundo del derecho comparado y nos invita a reflexionar sobre las influencias y relaciones entre distintos sistemas en el ámbito del derecho procesal penal. En un mundo globalizado la interacción entre diversos sistemas jurídicos resulta cada vez más intensa, las fronteras parecen haberse vuelto más tenues y el proceso penal no escapa a este fenómeno. En este marco, son numerosos los institutos y las soluciones estadounidenses que han sido importadas en distintas jurisdicciones europeas y latinoamericanas: la justicia negociada típica del pragmatismo estadounidense brinda un claro ejemplo. Aun así, cabe preguntarse si ello implica una "americanización" de los sistemas procesales referidos, o si, por el contrario, éstos han sabido conservar sus notas más características.

En este riguroso y exhaustivo trabajo, Langer polemiza contra la tesis de la "americanización" del proceso penal según la cual un número importante de sistemas legales gradualmente podrían imitar o parecerse al sistema legal estadounidense. Sin negar la influencia en el mundo de este último en los ámbitos más diversos del derecho, rápidamente prevé contra dicha 
tesis mediante un análisis del modo en que ha sido introducido el instituto estadounidense del plea bargaining en cuatro países de tradición continental europea y latinoamericana - Alemania, Italia, Francia y Argentina-.

El plea bargaining es un mecanismo procesal estadounidense a través del cual la fiscalía y la defensa pueden alcanzar un acuerdo sujeto a la aprobación de un tribunal en el marco de un proceso penal. El término suele traducirse al español como "acuerdo de culpabilidad negociado". Éste generalmente consiste en que el acusado se declara culpable de uno o más delitos a cambio de algunas concesiones: la fiscalía desestima otros cargos, o bien acepta que el acusado se declare culpable de un delito menor. De esta manera, el acusado evita su sujeción al juicio tradicional.

Luego de reconocer la influencia que ha tenido el plea bargaining estadounidense en estas cuatro jurisdicciones, Langer pone en evidencia las diferencias - incluso sustanciales - con el modelo estadounidense que la importación del instituto ha presentado en cada uno de esos países, lo que mostraría que lejos se está de que tal influencia esté efectivamente recreando la práctica estadounidense en otros sistemas legales.

A su turno, Lorena Bachmaier, Carlos Correa Robles y Armin Engländer enriquecen el debate desde las perspectivas de sus propios países. Ellos pertenecen a jurisdicciones que comparten una misma tradición (continental europea y latinoamericana $)^{1}$ que es aquella analizada en el trabajo central. De esta manera, contribuyen a la Discusión munidos de las experiencias legales de sus países de origen. Así, junto a la evaluación de la tesis de no-americanización presentada por Langer, la búsqueda de una metáfora que logre captar adecuadamente el fenómeno de la importación de prácticas legales extranjeras y el acierto o desacierto de las reformas analizadas resultan ser los puntos centrales de sus contribuciones.

\section{Sistema inquisitivo y adversarial: reconceptualización}

La temática analizada obliga a abordar diversas cuestiones preliminares. Y es que el interrogante planteado en torno a una posible americanización del

1 Bachmaier por España, Correa Robles por Chile y Engländer por Alemania. 
proceso penal en sistemas de tradición continental europea y latinoamericana conlleva la necesidad de establecer un marco conceptual que permita definir las características típicas del sistema procesal penal estadounidense -históricamente caracterizado como sistema acusatorio- por contraposición al sistema procesal penal de Europa continental y Latinoamérica - considerado un sistema inquisitivo-.

Ahora bien, la caracterización de estos sistemas no ha sido una tarea sencilla y aún hoy continúa suscitando interés y controversia. Ya en el siglo XII se utilizaba esta dicotomía para distinguir un proceso que requería el impulso de una parte para ponerse en marcha (processus per accusationem), de un proceso que podía iniciarse en su ausencia (processus per inquisitionem $)^{2}$. En tiempos modernos generalmente se ha sostenido que el rasgo diferencial entre el sistema de enjuiciamiento penal acusatorio y el inquisitivo obedece al modo en que se organizan los poderes ejercidos en el proceso. Así, la característica fundamental del sistema acusatorio residiría en la división de los poderes ejercidos en el proceso entre acusador, imputado y tribunal, mientras que la nota característica del sistema inquisitivo estaría dada por la concentración del poder procesal en una única mano, la del inquisidor ${ }^{3}$.

Como lo ha hecho ya en otra ocasión ${ }^{4}$, Langer se propone aquí echar luz sobre las diferencias entre el sistema penal acusatorio y el sistema penal inquisitivo ${ }^{5}$ a través de un análisis centrado en ciertos rasgos determinantes

2 Damaska, M. R., Las caras de la justicia y el poder del Estado. Análisis comparado del proceso legal, Santiago de Chile, Editorial Jurídica de Chile, 2000, p. 12.

3 Maier, J. B. J., Derecho Procesal Penal. Fundamentos, Buenos Aires, Ad Hoc, 2016, pp. 416421.

4 Langer, M., "La Dicotomía Acusatorio-Inquisitivo y la Importación de Mecanismos Procesales de la Tradición Jurídica Anglo-Sajona: Algunas Reflexiones a Partir del Procedimiento Abreviado", en Maier, J. B. J. y Bovino, A. (comps.), El procedimiento abreviado, Buenos Aires, Del Puerto, 2001, pp. 97-133. Véase también Carrió A., El enjuiciamiento penal en la argentina y en los Estados Unidos, Buenos Aires, Eudeba, 1990.

5 Cabe reiterar aquí la doble advertencia que realiza el autor desde el inicio del texto en el sentido de que por un lado, las expresiones "sistema acusatorio" y "sistema inquisitivo" son utilizadas como categorías meramente descriptivas y no como tipos ideales normativos; y de que, por el otro, no se pretende adoptar a través de ellas ningún tipo de connotación política o cultural, tal como ocurre con la tradicional asociación entre sistema acusatorio e inquisitivo y concepciones liberales o autoritarias del proceso penal, respectivamente. 
que la doctrina suele pasar por alto. En una descripción esencialmente compartida por los discutidores de su trabajo, explica que estas categorías no deben ser entendidas (o no sólo) como dos formas distintas de distribuir el poder y las responsabilidades entre los principales actores del proceso penal, sino más bien como dos culturas procesales distintas: a una la identificará con el "modelo de la disputa" y a la otra con el "modelo de la investigación oficial”.

Este marco teórico brindará las bases para comprender los efectos que genera el traslado de un instituto propio de un sistema al otro, a la vez que le permitirá a los contribuidores de esta Discusión evaluar si es o no cierto que, tal como se sostiene desde ciertos sectores, la adopción del plea bargaining estadounidense en los sistemas procesales europeos y latinoamericanos referidos ha desencadenado un avance de éstos en dirección al sistema acusatorio (tesis fuerte de la "americanización").

\section{Sobre trasplantes, traducciones y otras metáforas}

A la hora de analizar lo que ocurre cuando ideas o instituciones legales son transferidas desde un sistema legal a otro, la metáfora muy difundida y algo rígida del "trasplante legal" no lograría captar las transformaciones que tales ideas e instituciones pueden sufrir en el proceso de adaptación, ni tampoco las que dicho fenómeno puede generar en el sistema legal receptor. En efecto, ese legal borrowing no se agota en una mera reproducción del elemento foráneo en el sistema receptor, sino que implica necesariamente una transformación del instituto importado para adaptarlo al contexto jurídico e institucional en el que se inserta.

De allí la propuesta de Langer de la "traducción legal" como metáfora para comprender el fenómeno de la importación de prácticas legales extranjeras. Así pues, la práctica legal transferida (en este caso el plea bargaining) puede ser entendida como el texto que ha sido traducido de un idioma - el sistema acusatorio estadounidense - a otro idioma - los sistemas inquisitivos de Alemania, Italia, Argentina y Francia-. El objetivo de Langer es precisamente poner al descubierto el modo en el que la men- 
cionada importación se ha adaptado a los principios del modelo inquisitivo existente. Por lo demás, el enfoque de Langer presupone que la "americanización" no es un juego a todo o nada, en la medida en que las prácticas del sistema legal receptor pueden moverse en dirección del sistema estadounidense en un determinado nivel de procedimiento pero no en otro. Ello explica también su preferencia por la metáfora de la traducción legal como herramienta heurística superadora para captar esta realidad.

Sus discutidores, sin embargo, no se muestran tan convencidos. Ellos advierten, por un lado, acerca de la sobrevalorización de la potencia heurística de la metáfora propuesta por Langer. Por el otro, proponen una revalorización de la metáfora del "trasplante legal", cuya difusión debemos a Alan Watson. Así, Lorena Bachmaier, quien comparte casi por completo el análisis y la conclusión de la obra de Langer, en este punto no advierte una contradicción, sino una mera diferencia de enfoques entre ambos autores. En otras palabras, Watson no niega lo que Langer enfatiza. A su vez, Bachmaier extiende el análisis más allá, al retomar diversos enfoques que han querido constatar que el proceso penal europeo no sólo no se ha "americanizado", sino que incluso se ha "inmunizado" frente a la influencia estadounidense. Así, fórmulas de consenso y otros institutos típicamente adversariales habrían actuado como vacunas en los sistemas receptores. Ingeniosamente, la autora termina por sugerir que esta idea de inoculación subyace de algún modo también al trabajo de Langer.

\section{4. ¿Plea Bargaining como Caballo de Troya?}

En lo que resulta ser el núcleo del trabajo, Langer comienza por exponer cuáles han sido los fenómenos que han dado lugar a la llamada "tesis fuerte de la americanización”. Así pues, explica que en las últimas tres décadas, un gran número de países de Europa continental y Latinoamérica introdujeron reformas de corte acusatorio en sus sistemas típicamente inquisitivos. También los demás autores reconocen que el viejo sistema inquisitivo poco a poco ha comenzado a transitar hacia caminos que antes parecían vetados, aunque el análisis de las causas de este proceso no parece ser uniforme. 
De los trasplantes a las traducciones legales: Introducción a la tesis...

Especial relevancia cobra en este contexto la progresiva incorporación de diversos mecanismos consensuales inspirados en el plea bargaining. La elección por parte de Máximo Langer de este instituto como objeto de análisis luce más que acertada. En efecto, pocas prácticas resultan más características del sistema acusatorio estadounidense por contraposición al inquisitivo continental - al menos en el sentido en que son definidos a lo largo del texto ${ }^{6}$-en tanto a través de él el acusado al declararse culpable ("guilty plea") puede poner fin a la etapa de la determinación de la culpabilidad o inocencia y las partes — los verdaderos dueños del proceso-, mediante una negociación, alcanzar un acuerdo que no necesariamente reflejará la verdad de lo ocurrido y que un órgano decisor pasivo no tendría por qué rechazar. El plea bargaining, de hecho, parece incompatible con un sistema en el que no existe el concepto de declaración de culpabilidad, en donde el fiscal posee una discrecionalidad mucho más limitada para decidir qué casos habrá de perseguir, en donde la verdad es concebida en términos más absolutos, y en donde los jueces no suelen sentirse vinculados por las peticiones de las partes en cuanto a la pena que habrán de imponer.

No obstante esta aparente incompatibilidad, Langer explica que existe un gran número de países continental europeos y latinoamericanos que recientemente han traducido este mecanismo en sus procedimientos. Esto de por sí parece suficiente, a juicio del autor, para confirmar la tesis "débil" de la americanización. Pero además, podría pensarse que si los referidos países tradujeran este mecanismo fielmente, entonces se produciría un profundo cuestionamiento de las bases del sistema inquisitivo, y fiscalía y defensa comenzarían a sentirse partes en una disputa, mientras que el juez comenzaría a percibirse a sí mismo como un mero árbitro (tesis "fuerte" de

6 Efectúo esta aclaración puesto que algunos autores sostienen que el plea bargaining no resulta ser un instituto representativo del sistema acusatorio, sino más bien lo contrario, ver p. ej., Ferrajoli, L., Derecho y Razón, Madrid, Trotta, 2014, p. 748 y Anitua, G. I., "La importación de mecanismos consensuales del proceso estadounidense en las reformas procesales latinoamericanas", en Ensayos sobre enjuiciamiento penal, Buenos Aires, Del Puerto, 2014, p. 200 y ss. Sin embargo, es probable que ello obedezca al entendimiento de dicho sistema como un modelo puro, mientras que, como ya se ha dicho, Langer lo utiliza aquí como mera categoría descriptiva. Sobre las razones de la paradoja que implica rechazar este instituto propio del derecho anglosajón bajo la calificación del procedimiento como inquisitivo véase Langer, M, op. cit., pp. 109-111. 
la americanización). De este modo, el plea bargaining sería algo así como "un Caballo de Troya con el potencial de introducir, escondido en su interior, la lógica del sistema acusatorio en el inquisitivo" 7 .

A través del estudio de la legislación y la práctica jurídica de los países considerados, la propuesta de Langer persigue comprobar que la versión fuerte de la tesis de americanización es inaplicable, o, al menos, demasiado simplista. Parece, cuanto menos inverosímil que una única reforma de inspiración estadounidense tenga el poder de lograr que los actores de los procesos penales abandonen sus resabios inquisitivos. Esto mismo es evidenciado por Carlos Correa Robles, quien presenta las tensiones que ha generado la introducción de los acuerdos y destaca acabadamente los resguardos del legislador alemán y del legislador chileno a fin de mantener vigentes ciertos principios estructurales del proceso tradicional.

Entonces, lo que se habría modificado es en realidad el plea bargaining, que ha sido "traducido" para que pueda subsistir en el modelo receptor. Ello, a su vez, habría traído aparejado el efecto de fragmentación y divergencia en jurisdicciones que solían compartir una cultura procesal similar. Es precisamente respecto del modelo de la investigación oficial que las cuatro jurisdicciones analizadas estarían comenzando a diferir.

\section{Las razones de la ¿resistencia?}

Tal vez valga la pena indagar acerca de las razones que se esconden detrás del fenómeno de la no-americanización (en su versión fuerte), si es que se comparte la tesis de Langer. Así, las diferencias estructurales entre el modelo acusatorio penal estadounidense por un lado, y el inquisitivo continental europeo y latinoamericano por el otro, a juicio del autor son tan profundas que hacen poco probable que reformas individuales inspiradas en modelos estadounidenses empujen esos procesos penales inquisitivos

7 Ver punto V en Langer, M., “De los transplantes legales a las traducciones legales..., en Discusiones, en este número. 
De los trasplantes a las traducciones legales: Introducción a la tesis...

sustancialmente en la dirección del sistema acusatorio ${ }^{8}$. Esta diferencia en la cultura jurídica de tales países - "estructuras de interpretación y sentido inquisitivas preexistentes" - constituiría el factor principal que ha obstaculizado la aparente "americanización". Otras veces la resistencia local encontrada ante la reforma entre los diversos actores del proceso penal, o incluso la desconfianza de los propios impulsores de la importación han tenido un rol fundamental para neutralizar el riesgo de americanización. Y es que la introducción del plea bargaining lógicamente pudo ser visto como una amenaza al poder tradicional asegurado en un modelo inquisitivo. Pero además, quizá sea posible pensar en la preocupación de los riesgos que tales negociaciones podrían implicar en términos de debido proceso ${ }^{9}$.

El análisis anterior, sin embargo, nos compromete con una asunción que puede no estar libre de objeciones. ¿En qué medida se puede afirmar que la incorporación del juicio abreviado es verdaderamente una consecuencia de la influencia estadounidense en los modelos analizados? Es esto lo que Engländer pretende cuestionar, al indagar sobre los factores que habrían sido relevantes para la formación y proliferación del juicio abreviado en Alemania. El análisis propuesto por el autor parece com-

8 Si se piensa, tan sólo como ejemplo, en la introducción en el sistema procesal penal argentino de otra figura típica del pragmatismo estadounidense como es la del imputado "arrepentido" o colaborador (consolidada definitivamente por la Ley 27.304, B.O. 2/11/2016), se advierte que ella tampoco parece haber modificado el paradigma predominantemente inquisitivo, pues, pese a que tanto en el caso estadounidense como en el argentino el instituto constituye un incentivo para fines externos al proceso penal (p. ej., desbaratamiento de organizaciones criminales, protección de la competencia y del mercado, etc.), la práctica argentina parece sugerir que el instituto no es concebido como una negociación entre el imputado y la fiscalía, sino más bien como un beneficio que se le otorga al imputado, quien puede obtener la reducción de la escala penal a cambio de la "confesión" y la "colaboración" en la investigación oficial de los hechos.

9 Para una mirada crítica de los acuerdos en este sentido, además de la bibliografía señalada por Langer véase: en Alemania, Volk, K., Curso fundamental de Derecho Procesal Penal, Buenos Aires, Hammurabi, 2016, pp. 393-398 y Huber, B., "Últimas tendencias en materia de negociaciones en el proceso penal alemán”, Revista Penal, 22, 2008, pp. 43-49, disponible también en: https://dialnet.unirioja.es/servlet/articulo?codigo=2666898; en Italia, Ferrajoli, L., op. cit., pp. 737 y ss., 747 y ss. y 76; en Argentina, Anitua, G. I., op. cit., pp. 187-210 y "El juicio penal abreviado como uno de las reformas penales de inspiración estadounidense que posibilitan la expansión punitiva” en Maier, J. B. y Bovino, A. (comps.), El procedimiento abreviado, Buenos Aires, Del Puerto, 2001, pp. 137-160. 
partir la tesis principal de Langer (negación de la tesis "fuerte") al poner de relieve que el desarrollo que ha tenido el plea bargaining en Alemania desde la fecha de publicación del trabajo de Langer ha estado guiado por la máxima inquisitiva de obligación de la averiguación de la verdad, incluso como imperativo constitucional. Tras ello, sin embargo, Engländer ataca una de las premisas sobre las que se apoya esta tesis: la idea según la cual el desarrollo del procedimiento abreviado en Alemania puede reconducirse a la influencia del modelo estadounidense. De este modo, en la visión de Engländer incluso la tesis débil de la americanización queda sin sustento alguno. En este contexto, no es posible pasar por alto las observaciones de dos de los discutidores de este número, quienes señalan que en las jurisdicciones analizadas la importación de estas soluciones procesales negociadas constituyó una respuesta pragmática frente al aumento de la cantidad de casos penales en sistemas que resultaban directamente inviables, antes que una consecuencia de una profunda influencia cultural del sistema estadounidense. Si esto es correcto, entonces cabe preguntarse: ¿tiene sentido hablar de resistencia?

\section{Algunos interrogantes finales}

El trabajo de Máximo Langer demuestra un conocimiento cabal de los sistemas estudiados y un análisis de un grado de rigurosidad pocas veces visto. En este sentido, resulta dificultoso siquiera aproximar una evaluación crítica o novedosa de la cuestión planteada. El autor logra superar todo examen superficial que podría indicar que, al importar instituciones propias del proceso penal estadounidense, el proceso penal continental y latinoamericano se ha americanizado necesariamente. Y no se detiene allí, sino que además analiza el efecto paradigmático que la influencia estadounidense ha generado en los sistemas receptores.

Tal como correctamente subraya Bachmaier, el trabajo de Langer no propone una evaluación del éxito o fracaso, ni de la conveniencia o no de la incorporación de estas formas de justicia negociada en las jurisdicciones examinadas. Su objetivo es analizar el impacto y los efectos de este 
De los trasplantes a las traducciones legales: Introducción a la tesis...

fenómeno: el modo en que ha sido recepcionado el plea bargaining con prescindencia de aquella dicotomía. También Engländer se coloca en esta línea para el caso de Alemania. En ello se distancia de los otros discutidores, quienes en mayor o menor medida realizan un juicio de valor del instituto en sí. Correa Robles, por ejemplo, no oculta su preocupación por las tensiones que suscita la incorporación del plea bargaining en relación con las garantías del debido proceso, y, a través de una comparación de costos y beneficios, analiza el acierto de las reformas alemanas y chilenas desde una mirada crítica y escéptica. Más optimista, en cambio, es la visión de Bachmaier en relación con la incorporación de estas fórmulas de consenso en el sistema europeo, sobre todo en términos de eficiencia, pero también desde la perspectiva de las garantías fundamentales del acusado. De este modo, sus discutidores logran, en un diálogo constante con Langer, extender aún más el análisis e incluso cuestionar algunas premisas que subyacen a la tesis y al trabajo principal de este volumen.

Para finalizar, solamente agregaré unos comentarios y plantearé algunos interrogantes que la lectura de esta Discusión me ha suscitado. En primer lugar, y focalizando la atención una vez más sobre el uso de metáforas, comparto con Langer que la metáfora de la traducción legal resulta superadora de la tradicional puesto que logra captar de forma más clara el proceso de transformación de prácticas e instituciones legales al ser trasladadas a otros sistemas (el "texto" debe ser adaptado al "idioma” receptor y allí se juega el proceso legislativo de importación del instituto en cuestión). A esto lo llamaré "primer momento". Lo que no me parece tan asumible, en cambio, es que esa misma metáfora sea igual de efectiva para expresar el "segundo momento" que Langer pretende enfatizar, el de la aplicación del instituto que puede producir una sucesión de cambios una vez que ha sido incorporado en el sistema de destino. Pues, una vez realizada la traducción, no veo cómo ese texto pueda producir cambios en el idioma receptor. $\mathrm{O}$ al menos no creo que la metáfora de la traducción resulte la más expresiva de esa realidad. Por el contrario, considero que se requiere un concepto más dinámico, que pueda captar el sentido de las transformaciones que conlleva la aplicación de la institución importada.

Tal vez sea posible pensar en un injerto medicinal que implica trasladar tejido de una parte del cuerpo a otra, o de una persona a otra, sin 
llevar su propio riego sanguíneo con él. Previo a ello, el material de injerto debe ser preparado a fin de no ser rechazado por el lecho receptor (primer momento). Finalmente, de producirse exitosamente el injerto, se desarrollará un nuevo sistema de irrigación sanguínea en la zona donde se lo coloca (segundo momento). A su vez, el injerto es diferente al trasplante en el sentido de que, mientras el trasplante no requiere una modificación o adaptación del órgano que será trasplantado, el injerto exige una preparación a fin de ser privado totalmente de su aporte sanguíneo (ej. disección y desgrase de la dermis en injertos de piel). Asimismo, mientras en el trasplante se trata solamente de cambiar un órgano por otro, sin que se esperen transformaciones o modificaciones, el injerto, una vez realizado, comienza a mimetizarse y a crear nuevas condiciones biológicas sobre la persona, a adaptarse al terreno donde ha sido colocado, a cambiar de tamaño, a generar neovascularización, es decir, adquiere vida propia con un dinamismo biológico que no se encuentra presente en los trasplantes de órganos. Por otra parte, la metáfora del injerto podría también responder a las objeciones efectuadas al "irritante legal" de Teubner puesto que el injerto proviene de un organismo distinto, externo al que lo recepta. Según el procedimiento de injerto entonces, se toma un cuerpo extraño y distinto al de destino (plea bargaining), pero con la potencialidad de seguir produciendo cosas y modificando otras una vez que se lo injerta en el organismo receptor (sistema inquisitivo). Así, bien podría hacerse alusión a un "injerto legal".

En segundo lugar, creo que el análisis realizado hace incuestionable la conclusión a la que se llega en el trabajo central. Aun así, subsiste la pregunta de si el fenómeno descripto por Langer no podría constituir el comienzo de la denominada "americanización", incluso en su versión fuerte. Es decir, las crecientes reformas de corte acusatorio en las jurisdicciones examinadas no parecen, actualmente (y tal vez todavía), haber alterado las bases de sus sistemas inquisitivos; sin embargo, si se mantienen y acrecientan en el tiempo, ¿podrían llegar a promover la concepción estadounidense del proceso penal en esas jurisdicciones? ¿O las diferencias entre el sistema acusatorio e inquisitivo son tan profundas que ello sería inviable? ¿Podría ser considerada esta etapa como una mera etapa de transición hacia una verdadera americanización? En este sentido, retomando 
De los trasplantes a las traducciones legales: Introducción a la tesis...

la metáfora tradicional del trasplante legal, no cabe pasar por alto que los casos de trasplantes se encuentran siempre precedidos por un examen de histocompatibilidad, lo que sugiere que de algún modo, el cuerpo receptor se encuentra preparado para recibir el órgano de que se trate. De modo similar, ¿podría considerarse que las culturas legales importadoras del plea bargaining en algún punto resultan compatibles con cierta concepción del sistema acusatorio?

Parecería que no, pero quizá valga la pena preguntárselo. Sobre todo si se piensa en la asociación entre plea bargaining y la técnica más tradicional del sistema inquisitivo como prueba suficiente para la determinación de la culpabilidad: la confesión ${ }^{10}$. Pero aun teniendo en cuenta los rasgos característicos de los sistemas inquisitivos modernos, en la práctica es posible advertir cierto paralelismo entre el proceso penal estadounidense y el continental europeo o latinoamericano en la medida en que en Estados Unidos, la difundidísima práctica del plea bargaining hace que en la casi totalidad de los casos la decisión acerca de la responsabilidad del imputado no se lleve a cabo ante un tribunal pasivo, sino en las oficinas del fiscal, que termina por actuar como juez en su propio caso. En efecto, la mayoría

${ }^{10}$ Así se ha dicho: "El carácter inquisitivo del 'juicio abreviado' pone de manifiesto la intención de condenar sobre la base de la confesión extraída coactivamente”, Bovino, A., "Procedimiento abreviado y juicio por jurados", en Maier, J. B. y Bovino, A. (comps.), El procedimiento abreviado, Buenos Aires, Del Puerto, 2001, p. 74. Así también, Ferrrajoli: "La negociación entre acusación y defensa es exactamente lo contrario al juicio contradictorio característico del método acusatorio y remite, más bien, a las prácticas persuasorias permitidas por el secreto en las relaciones desiguales propias de la inquisición", Ferrajoli, L., op. cit., p. 748. Se ha dicho también: "El procedimiento abreviado supone una clara regresión al juzgamiento escrito y reverdece la figura de la confesión, tan cara a la ideología del inquisitivo", Almeyra, M. A., "Juicio abreviado ¿̇o la vuelta al inquisitivo?”, en La Ley, F-6, Buenos Aires, 1997. En igual sentido, Cabezudo Rodríguez analiza con detenimiento los mecanismos de negociación, encontrando paralelismos entre el recurso de acusar por delitos no realizados y solicitar penas gravísimas o demostrar que las conseguirán indudablemente en juicio (el overcharging y el bluffing) de los fiscales estadounidenses, y el fingimiento de pruebas inexistentes por los inquisidores con la promesa de una solución más piadosa si se aviniera a prestar la confesión, cf. Cabezudo Rodríguez, N., El Ministerio Público y la justicia negociada en los Estados Unidos de Norteamérica, Granada, Comares, 1996, los últimos dos cit. por Anitua, G. I., Ensayos sobre enjuiciamiento penal, op. cit., pp. 201 y 203. Esta asociación es también sugerida por Correa Robles en su réplica al texto de Langer en este volumen de Discusiones y por el propio Langer en el texto principal. 
de los acusados en los Estados Unidos son condenados efectivamente por funcionarios públicos y no, en cambio, por jueces independientes y jurados legos. Entonces, si dejamos de lado por un momento la concepción del fiscal como una parte de un procedimiento acusatorio judicial, y nos concentramos en la función del fiscal en la etapa de investigación, resulta bastante sencillo reimaginar al fiscal como el agente de un proceso inquisitivo estatal para determinar los hechos y establecer la culpabilidad de las personas ${ }^{11}$. Las imágenes que invoca el verbo "negociar" resultan en cierta manera engañosas puesto que es dudoso que el fiscal intervenga en estos procesos como representante de un interés que negocia en igualdad de condiciones con su contraparte.

En resumen, tal vez exista cierta compatibilidad entre los dos sistemas. Quizá haya que matizar lo sostenido en torno al plea bargaining como una de las prácticas más incompatibles con el sistema inquisitivo, en razón de la pretensión de eficacia que en la actualidad caracteriza a todo sistema procesal penal. O tal vez Engländer tenga razón y no haya que sobrestimar el potencial estadounidense para influenciar otros sistemas jurídicos. Pero no es éste el espacio para responderlo. Aquí sólo se ha querido presentar la Discusión y destacar el ingenio de los autores que han contribuido a ella. Se trata, en el fondo, de un debate sobre culturas legales, y más específicamente, sobre la manera en que es concebido el proceso penal y el modo en que han tenido o no lugar las influencias entre distintos sistemas jurídicos. A partir de ahora el lector podrá sacar sus propias conclusiones.

${ }^{11}$ Lynch, G. E., "Plea bargaining: el sistema no contradictorio de justicia penal en Estados Unidos", en Nueva Doctrina Penal, 1998/A., Buenos Aires, Del Puerto, 2001, pp. 299 y 307, traducción de Natalia Sergi, disponible también en http://upauderecho2.blogspot. com/2008/05/plea-bargaining-el-sistema-no.html. Este autor se opone a quienes pretenden "europeizar" la justicia estadounidense ya que sostiene que, en los hechos, ésta ya tiene una estructura administrativa donde un funcionario (el fiscal en lugar del juez de instrucción) procesa los casos penales. 
De los trasplantes a las traducciones legales: Introducción a la tesis...

\section{Bibliografía}

Almeyda, M.A., "Juicio abreviado ¿o la vuelta al inquisitivo?, en La Ley, F-6, Buenos aires, 1997.

Anitua G. I., "La importación de mecanismos consensuales del proceso estadounidense en las reformas procesales latinoamericanas", en Ensayos sobre enjuiciamiento penal, Buenos Aires, Del Puerto, 2014 y "El juicio penal abreviado como uno de las reformas penales de inspiración estadounidense que posibilitan la expansión punitiva”, en Maier J. B. y Bovino A. (comps.), El procedimiento abreviado, Buenos Aires, Del Puerto, 2001, pp. 137-160, ISBN 987-9120-41-8.

Bovino A., "Procedimiento abreviado y juicio por jurados", en Maier J. B. y Bovino A. (comps.), El procedimiento abreviado, Buenos Aires, Del Puerto, 2001, pp. 53-96.

Carrió A., El enjuiciamiento penal en la argentina y en los Estados Unidos, Buenos Aires, Eudeba, 1990.

Cabezudo Rodríguez, N., El Ministerio Público y la justicia negociada en los Estados Unidos de Norteamérica, Granada, Comares, 1996.

Damaska, M. R., Las caras de la justicia y el poder del Estado, Análisis comparado del proceso legal, Santiago de Chile, Editorial Jurídica de Chile, 2000.

Ferrajoli L., Derecho y Razón, Madrid, Trotta, 2014.

Huber B., "Últimas tendencias en materia de negociaciones en el proceso penal alemán”, en Revista Penal, 22, 2008, pp. 43-49, disponible en: https://dialnet.unirioja.es/servlet/articulo?codigo $=266689$

Langer, M., "La Dicotomía Acusatorio-Inquisitivo y la Importación de Mecanismos Procesales de la Tradición Jurídica Anglo-Sajona: Algunas Reflexiones a Partir del Procedimiento Abreviado", en Maier J. B. J. y Bovino A. (comps.), El procedimiento abreviado, Buenos Aires, Del Puerto, 2001, pp. 97-133.

Lynch, G. E., "Plea bargaining: el sistema no contradictorio de justicia penal en Estados Unidos", en Nueva Doctrina Penal, 1998/A, Buenos Aires, Del Puerto, 2001, pp. 293-330, disponible también en http://upauderecho2. blogspot.com/2008/05/plea-bargaining-el-sistema-no.html. 
Antonella Donnes

Maier, J. B. J., Derecho Procesal Penal. Fundamentos, Buenos Aires, Ad Hoc, 2016.

Volk K., Curso fundamental de Derecho Procesal Penal, Buenos Aires, Hammurabi, 2016. 